\title{
Trajectory of Top-Dross Particles During the Melting of Zinc Ingot in Galvanizing Pot
}

\author{
Ronaldo Rodrigues Vieira ${ }^{a *}$ (1), Izabela Diniz Duarte ${ }^{a}$, Henrique Lacerda Eleutério ${ }^{b}$, \\ Thalisson Gustavo de Oliveirac ${ }^{c}$, Maurício Covcevich Bagatini ${ }^{d}$ (D), Roberto Parreiras Tavares ${ }^{d}$ (D) \\ ${ }^{a}$ Unigal Usiminas, Avenida Pedro Linhares Gomes, 5431, Ipatinga, MG, Brasil. \\ ${ }^{b}$ Centro de Pesquisa e Desenvolvimento da Usiminas, Avenida Pedro Linhares Gomes, 5431, \\ Ipatinga, $M G$, Brasil. \\ 'Instituto ESSS, Rua Orlando Phillippi, 100, Florianópolis, SC, Brasil. \\ 'Universidade Federal de Minas Gerais, Departamento de Metalurgia, Avenida Antonio Carlos, 6627, \\ 31270-900, Belo Horizonte, MG, Brasil.
}

Received: August 9, 2021; Revised: November 3, 2021; Accepted: November 29, 2021.

\begin{abstract}
The production of hot-dip galvanized steel presents great challenges, because it is currently the main raw material in the manufacturing of automobiles, and its surface quality is fundamental for the construction of automobiles. Obtaining the best surface appearance in galvanized steels is directly related to understanding the phenomena involved in the galvanizing process. In this process, achieving thermal and chemical stability of the galvanizing pot means keeping topdross formation under control. The top-dross is the main problem to be controlled, because it impacts the surface quality of coated steel. Some studies have been conducted to understand the formation of top-dross particles into the zinc bath, but little is known about the path of the particles formed from the melting ingots. In this study, the trajectories of these particles were simulated. It has been found that, depending on the immersion depth, dross particles may have different destinations.
\end{abstract}

Keywords: Computational Simulation, Mathematical Model, Hot Galvanizing, Dross.

\section{Introduction}

In response to the large increase in the use of non-ferrous and non-metallic materials by manufacturers of automobiles in the construction of its models seeking weight reduction and making the most efficient vehicles, the steel industries have developed new steel. Characteristics such as high conformability, mechanical strength and corrosion resistance were reconciled, the latter introduced through the metallic coating step on the steel surface. Hot dip galvanizing is currently the main metallic coating method for the production of galvanized steel, with pure zinc being the most used coating due to its cathodic protection on the steel and its good surface appearance after the galvanizing step ${ }^{1}$. In hotdip galvanizing lines it is possible to produce galvanized materials with various types of coating with zinc alloys or pure zinc (GI - galvanized). Of all the coating possibilities, the most widely used is the GI coating, which is the main coated steel used by European and North American automakers ${ }^{1}$.

The production of hot-dip galvanized steels presents great challenges to steel mills, because not all phenomena involved in the galvanizing process have been fully explored and understood, and those that are known are not well disseminated into the public domain literature. It is currently known that top-dross drag, which is the best known and main defect that can occur on the surface of the galvanized sheet during the coating process, can have various shapes and dimensions. The defect is formed by the combinations

*e-mail: ronaldo.rodrigues@unigalusiminas.com between $\mathrm{Fe}$, provided by the steel strip in process, with $\mathrm{Al}$ and $\mathrm{Zn}$, which make up the galvanizing bath and can find the strip in different positions inside the zinc bath ${ }^{2,3,4}$. In recent years, some studies have been developed to understand the phenomena that involve top-dross generation inside the zinc bath. Some investigated the effects of zinc flux in the bath for a given zinc pot layout, in one of these studies it was proposed the placement of barriers to prevent the formation of vortices ${ }^{5}$. Other studies were conducted with thermodynamic analysis of the formation of these particles, finding the effect of the relationship between the temperature and the solubility of Fe and $\mathrm{Al}$ in the zinc bath ${ }^{6}$ and the influence of the inlet temperature of the steel strip in the zinc bath in the higher formation of dross ${ }^{7}$. In these studies, controls for these parameters were proposed with good results in reducing the formation of top-dross particles, as it improved the stability of the process by reducing temperature and chemical composition variations in the hot dip galvanizing bath.

To support the studies, computational models were used using computer simulation software, the most common being CFD (Computational Fluid Dynamics) such as Ansys CFX or Fluent, which use the finite volume method for modeling and calculation. These models have a high potential to represent industrial process conditions and facilitate the understanding of the phenomena involved in the galvanizing process without the need to carry out industrial tests that could jeopardize production, product quality and increase operating costs. In addition, the software makes it possible to make modifications to the pot layout and observe its 
effects, without the need to carry out such modifications in an industrial pot that require a high investment and time.

As it is already known, it is not possible to prevent the formation of dross in the zinc pot, but only to control it ${ }^{8}$. The legacy of the studies already developed and mentioned above make it very clear that the two main sources of dross formation are changes in the chemical composition and/or temperature reduction of the zinc bath, which directly alter the solubility of Fe and Al. These events can be triggered by the temperature difference between the strip and the bath or by the melting of the ingot that is immersed to replace the zinc consumed by the strip in process ${ }^{9,10}$. However, the immersion depth of solid zinc ingot at room temperature and the influence on the formation of top-dross particles as well as their trajectories after they are formed, close to the ingot melting front, have not been widely studied. The aim of the present study is to map, through computer simulation, the trajectories of top-dross particles generated from different levels of immersion of the zinc ingot and compare the results with data from a different industrial plant.

\section{Experimental}

\subsection{Computer simulation}

In the present study, the displacement directions of top-dross particles $\left(\mathrm{Fe}_{2} \mathrm{Al}_{5} \mathrm{Zn}_{\mathrm{x}}\right)^{11}$ were simulated in a $3 \mathrm{D}$ computational model under three different conditions of immersion of the zinc ingot: $100 \%$ immersion in the galvanizing bath (Figure 1), 50\% immersion and 25\% immersion.

To carry out the simulations, the ANSYS Fluent software was used, with the turbulence model $\mathrm{k}-\varepsilon$ Realizable, which uses the equation for turbulent viscosity $\mu_{t}$

$$
\mu_{t}=\rho C_{\mu} \frac{k^{2}}{\varepsilon}
$$

Where $k$ is the turbulent kinetic energy, $\varepsilon$ is the dissipation rate of the turbulent kinetic energy, $\rho$ is the fluid density and $\mathrm{C}_{\mu}$ is constant in the $k-\varepsilon$ Realizable model which is a function of turbulence, deformation rates and average rotation of the flow.

The results of the liquid zinc flow lines from the pot with the electrical inductors that maintain the temperature

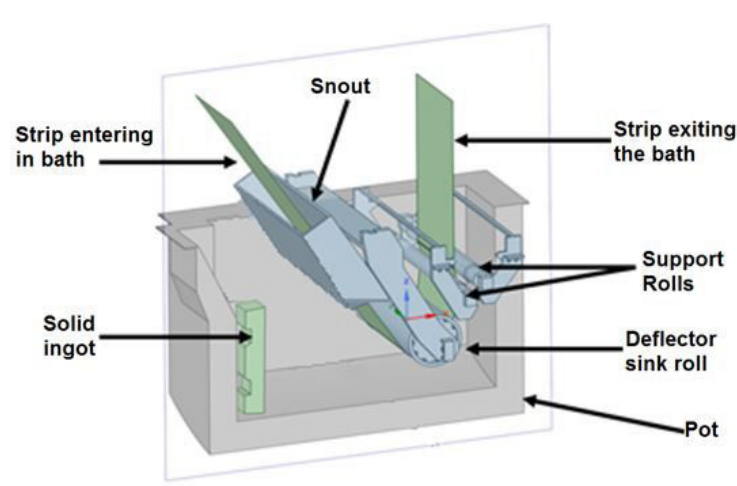

Figure 1. Basic layout of a galvanizing pot with ingot $100 \%$ immersed in the bath. of the zinc bath and which, which when in operation change the flow behavior, were compared with the results already known in the literature to confirm the flow pattern ${ }^{12}$.

The melting of the ingot with different levels of immersion was simulated in a transient regime, starting from a solid zinc ingot at $40^{\circ} \mathrm{C}$ and a liquid zinc bath at $460^{\circ} \mathrm{C}$, according to industrial operational practice. For this purpose, the liquid zinc bath was considered in Ansys Fluent as one domain and the solid zinc ingot as another, and these two domains shared their faces and these faces are totally permeable to energy and mass fluxes. The behavior of the density variation and the effects of this variation were calculated using the Boussinesq approximation ${ }^{13,14,15}$.

To trace the direction lines of the particles, the Discrete Phase Model (DPM) of one way (also known as the Lagrangian model) was used. This model considers the buoyant forces and viscosity of the liquid zinc acting on the particles, but does not consider the forces of the top-dross particles in the zinc, as they have negligible mass in relation to the mass of the zinc flow and its contributions to the flow they are also considered negligible.

In this model, time steps of $20 \mathrm{~s}, 16 \mathrm{~s}, 12 \mathrm{~s}, 10 \mathrm{~s}$ and $8 \mathrm{~s}$ were tested, all with 20 iterations per time step. Thus, it was found that for times longer than $12 \mathrm{~s}$, not all phenomena could be observed and the results did not converge, so the condition of $10 \mathrm{~s}$ was adopted with the maximum number of 5,000 steps to calculate the trajectory of the particles.

Mesh independence tests were performed varying the maximum mesh element size from $320 \mathrm{~mm}$ to $50 \mathrm{~mm}$ and for sizes smaller than $50 \mathrm{~mm}$, from which no variations were observed in the flow directions and speeds. The RMS (root-mean-square) convergence criterion adopted was 10-5.

The simulation was performed with the chosen pot model where the mesh consisted of 1,263,949 elements and $6,631,978$ nodes, as seen in Figure 2. The type of element used was the polyhedral. The computation processing time for the simulation was $245 \mathrm{~h}$, representing $30 \mathrm{~min}$ of the process of an industrial galvanizing pot, for which a computer with an Intel Xeon 3.6GHz processor was used, with 6 physical cores and a board with $32 \mathrm{~Gb}$ of RAM memory.

The molten zinc was considered an incompressible fluid that behaves as a Newtonian fluid. The flux of liquid zinc in the bath is described by the Navier-Stokes equations adapted to turbulent flow (2 and 3);

$\rho \frac{D u}{D t}=-\nabla \rho+\nabla[2(\mu+\mu t) \dot{\gamma}(\mu)]-\rho g$

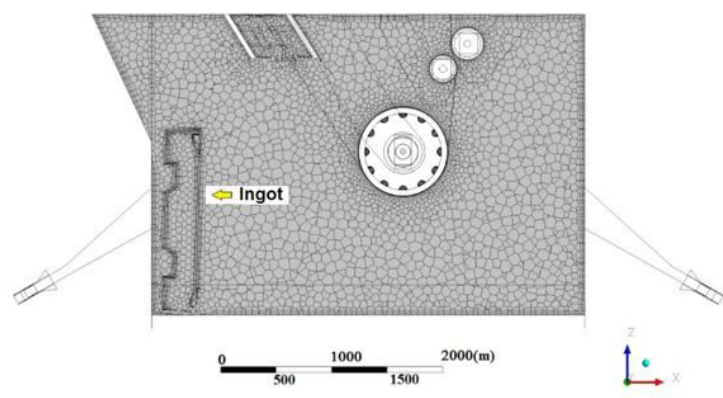

Figure 2. Mesh structure of polyhedral elements for zinc bath and ingot. 
$\nabla \mathrm{u}=0$

Where $\dot{\gamma}$ is the fluid deformation rate, $\rho$ is the fluid density, $\mathrm{g}$ is the gravitational constant, $\mu$ is the fluid viscosity and $\mu \mathrm{t}$ the turbulent viscosity. The flow regime is transient, turbulent and the equations that govern the kinetic energy of turbulence and the rate of dissipation of this energy are:

$\rho \frac{D k}{D t}=\nabla \cdot\left[\left(\mu+\frac{\mu_{T}}{\sigma_{k}}\right) \nabla k\right]+P+G-\rho \varepsilon$

$\rho \frac{D \varepsilon}{D t}=\nabla \cdot\left[\left(\mu+\frac{\mu_{T}}{\sigma_{\varepsilon}}\right) \nabla \varepsilon\right]+C \varepsilon l \frac{\varepsilon}{k}(P+G)-C_{\varepsilon 2 \rho} \frac{\varepsilon^{2}}{k}$

Where $\sigma_{\mathrm{k}}=1.0, \sigma_{\varepsilon}=1.3, \mathrm{C} \varepsilon 1=1.44, \mathrm{C} \varepsilon 2=1.92, \mathrm{P}$ is defined as the shear production and $\mathrm{G}$ is the effect of buoyancy on the production of turbulence $\mathrm{e}^{16,17}$.

The numerical method of finite volumes used the SIMPLE algorithm ${ }^{16,17}$ as the solution of the relevant equations. The choice of the discretization method was based on the methods most used in publications ${ }^{16,17}$. Pressure was discretized with the standard scheme, while momentum, turbulent kinetic energy, turbulent dissipation rate and energy equations are discretized with the first-order upwind scheme ${ }^{16,17,18}$.

The definitions of the conditions for simulation, known as boundary conditions, were carried out according to what was desired to observe, for example in which directions the particles move, where they precipitate and in which position within the zinc bath they found the strip of steel in process. These conditions are:

- Zinc velocity in the inductors generated with the momentum and temperature by source terms to reach the velocity of $2 \mathrm{~m} / \mathrm{s}^{19,20}$;

- $\quad$ Speed of the strip in process $2.5 \mathrm{~m} / \mathrm{s}$;

- Dimension of the strip in process: $0.70 \mathrm{~mm}$ thick by $1300 \mathrm{~mm}$ wide;

- $\quad$ Length of the submerged strip: $4.02 \mathrm{~m}$;

- Particles injected into the zinc ingot fusion front;

- There is no relative movement between the strip and the submerged rollers;

- Zinc bath surface defined as the top-dross removal region;

- $\quad$ Strip surface defined as the top-dross trapping region;
- Disregarded top-dross adhesion on roller surface;

- Adhesion of top-dross to the walls of the pot and structure of the arms of the rollers disregarded;

- Ingot mass to be cast of $1 \mathrm{t}$ with a length of $1.65 \mathrm{~m}$, width of $340 \mathrm{~mm}$ and height of $296 \mathrm{~mm}$;

The other conditions involving the physical properties of solid zinc, liquid zinc and top-dross particles can be seen in Table 1.

The strip was divided into 4 regions, Figure 3, to better map the amount of top-dross particles carried to each region of the strip by the zinc flow. Figure 3 also identifies the stabilizer rollers and deflector roller, which are submerged in the zinc bath and also the snout region.

The pot used as a simulation model has the following dimensional configuration: H1 (distance between the center of the back inductor and the side of the pot) $=900 \mathrm{~mm}$; H2 (distance between the center of the front inductor and the sides of the pot) $=1795 \mathrm{~mm}$; H3 (side elevation of the pot) $=3900 \mathrm{~mm}$; H4 (height of the inductor in relation to the bottom of the pot) $=1240 \mathrm{~mm}$; H5 (depth of the inductors in relation to the pot edge) $=1585 \mathrm{~mm}$ and $\alpha$ (inclination of the inductors in relation to the pot $)=60^{\circ}$, capacity for $250 \mathrm{t}$ of molten zinc, as shown in Figures 4 and 5.

\subsection{Validation of results on an industrial scale}

The simulation results were correlated with the results of surface quality of the galvanized strip, in relation to the

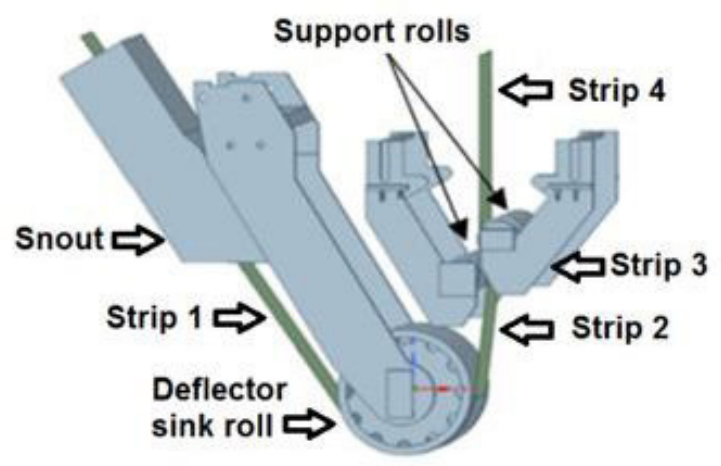

Figure 3. Definition of regions inside the zinc bath.

Table 1. Properties of top-dross particles and molten zinc.

\begin{tabular}{lcc}
\hline Viscosity ${ }^{21}$ of zinc & $3,85 \times 10^{-3}$ & Pa.s \\
\hline Zinc melting point & 420 & ${ }^{\circ} \mathrm{C}$ \\
\hline Thermal Expansion Coefficient of Zinc & $3,0 \mathrm{e}^{-5}$ & $1 / \mathrm{K}$ \\
\hline Thermal conductivity of zinc & 60 & $\mathrm{~W} / \mathrm{m}-\mathrm{K}$ \\
\hline Specific heat of zinc & 512 & $\mathrm{~J} / \mathrm{kg}-\mathrm{K}$ \\
\hline Top-dross temperature & 460 & ${ }^{\circ} \mathrm{C}$ \\
\hline Density ${ }^{22}$ of liquid zinc & 4200 & $\mathrm{~kg} / \mathrm{m}^{3}$ \\
\hline Liquid zinc temperature & 460 & ${ }^{\circ} \mathrm{C}$ \\
\hline Solid zinc temperature & 40 & ${ }^{\circ} \mathrm{C}$ \\
\hline Density ${ }^{22}$ of liquid zinc & $\mathrm{kg} / \mathrm{m}^{3}$ \\
\hline Density ${ }^{22}$ of solid zinc & 6650 & $\mathrm{~kg} / \mathrm{m}^{3}$ \\
\hline Zinc Melting Enthalpy & 7130 & $\mathrm{~J} / \mathrm{kg}$ \\
\hline Top-dross particle injection rate ${ }^{23,24}$ & 112000 & $\mathrm{~kg} / \mathrm{s} ;$ \\
\hline Diameter of top-dross particles & $2,16 \times 10^{-4}$ & $\mu \mathrm{m}$
\end{tabular}


dross drag defect, on an industrial scale. The computational model was built in three dimensions at the same scales as industrial equipment.

In order to confirm the simulation results, the results of the industrial process were monitored by inserting the ingots according to the simulated conditions. For this purpose, three forms of ingot insertion were used, complete, partial in $50 \%$ and partial in $25 \%$.

The inductors were kept at $400 \mathrm{~kW}$ after ingot insertion to reproduce the same velocity of $2 \mathrm{~m} / \mathrm{s}$ in the zinc flux used in the computational simulation. Some steel strip coils were selected, intended for testing, with the same dimensions used in computer simulation.

Industrial production was carried out under the same conditions as the process parameters of the simulation performed in ANSYS Fluent software. The production line chosen to carry out tests to confirm the results of the computer simulation was the galvanizing line no. 1 by Unigal LTDA, a company belonging to the Usiminas SA group.

After the hot dip galvanizing process, the materials were inspected on a rewind and inspection line to quantify the number of particles entrained by the strip during the galvanizing process. During inspection, each top-dross particle seen on the strip at a length of $100 \mathrm{~m}$ was considered as $1 \%$ dross drag occurrence. The inspection speed and number of times the line was stopped for a more detailed check of the occurrences were in accordance with the company's internal inspection procedures.

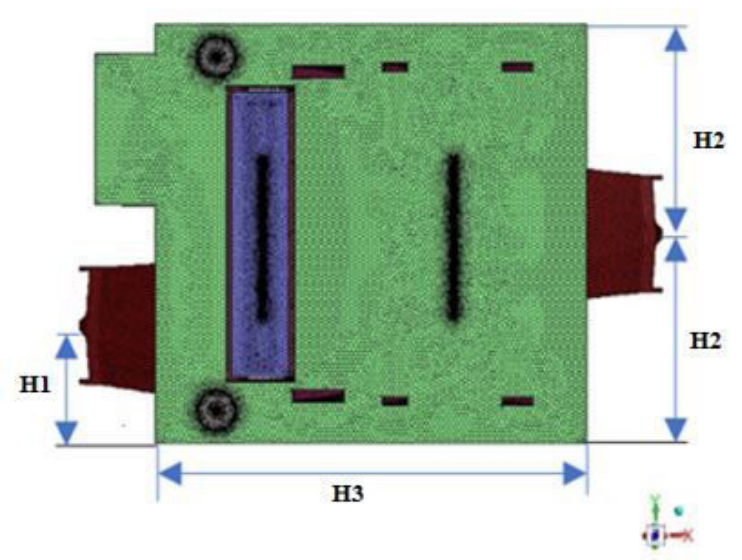

Figure 4. Top view of the pot used as a simulation model.

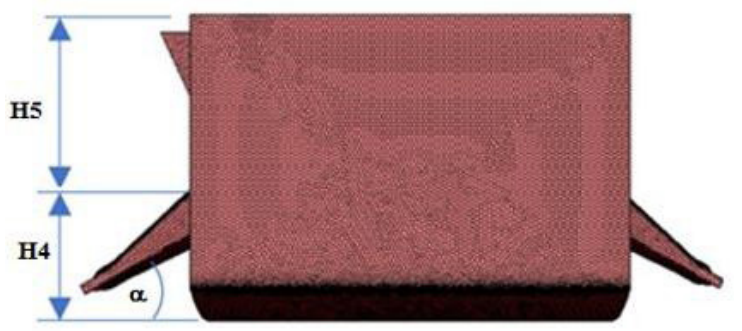

1.

Figure 5. Side view of the pot used as a simulation model.
Some samples of the defects found were taken and visually identified as top-dross particles for characterization via scanning electron microscopy with energy dispersive spectroscopy, SEM/EDS.

\section{Results and Discussion}

\subsection{Effect of ingot melting on the thermal profile of the bath}

The flow pattern of the liquid zinc inside the zinc pot can be seen in Figure 6, where there is a cut plane drawn in such a way that it was possible to display the two inductors of the pot, where the vectors indicate the direction of the displacement of the zinc flow. The analysis of the pot's flow pattern revealed that in the simulated parameter settings, no regions with the fluid at rest were found, that is, there are no dead zones inside the zinc bath. The speeds found throughout the zinc bath ranged from $1 \times 10^{-4} \mathrm{~m} / \mathrm{s}$ to $2.5 \mathrm{~m} / \mathrm{s}$, with the lowest speeds being in the regions close to the bottom of the pot and the highest speeds close to the strip. Specifically in this cut plane seen in Figure 6, the speeds varied between $1.26 \times 10^{-3} \mathrm{~m} / \mathrm{s}$ and $1.66 \mathrm{~m} / \mathrm{s}$.

Still observing Figure 6, it can be seen that in regions 1 and 2 there is formation of vortices caused by the fluid dragged by the strip, by one of the stabilizer rollers and by the zinc flow coming out of the electric heating inductor. In region 3 there is a flow that helps the formation of two recirculation zones of regions 1 and 2 . In region 4 there is an upward flow towards the strip and the snout. In region 6 the vectors are more aligned orthogonally to the observation plane. In region 7 the upward flow ends and becomes a vortex close to the bath surface. With all this internal motion in the zinc bath it is possible to understand that dross particles formed may follow different directions until they precipitate on the surface of the pot.

During the ingot melting simulations, significant temperature variations were recorded, as observed in Figure 7, where a cutting plane can be seen passing through the region where the ingot is at the initial moment of the melting. It is possible to observe that lower temperatures begin to appear as one approaches the ingot that was immersed at a temperature of $40^{\circ} \mathrm{C}$ in the zinc bath, which initially had a homogeneous temperature of $460^{\circ} \mathrm{C}$. In Figure 8 the same cutting plane

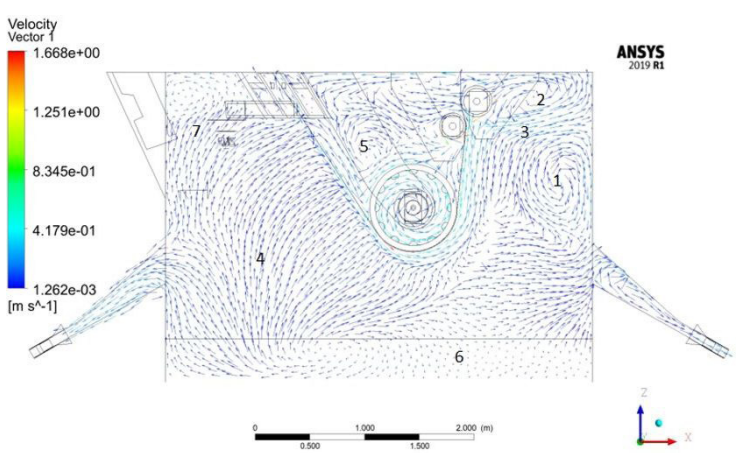

Figure 6. Flow pattern of the zinc bath in the galvanizing pot in a sectional plane showing the pot and the two inductors in the pot. 


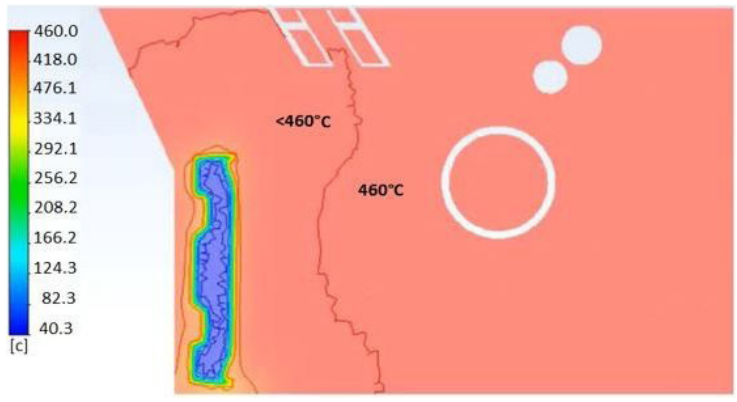

Figure 7. Temperature distribution with the solid ingot at $40^{\circ} \mathrm{C}$ fully inserted into the zinc bath.

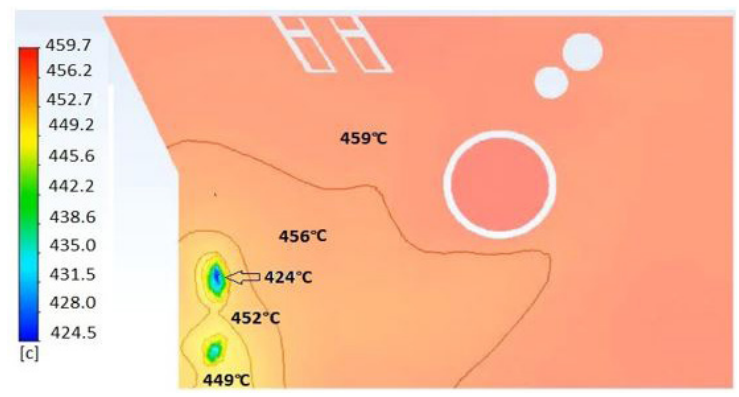

Figure 8. Temperature distribution after complete melting of the ingot inserted into the zinc bath after $7.7 \mathrm{~min}$.

seen in Figure 7 can be seen, but with the final moment of the ingot melting, which lasted $7.7 \mathrm{~min}$ and caused a very significant thermal heterogeneity in the bath. In this Figure it is possible to observe delineations of regions with different temperatures of zinc in the liquid state ranging from $424.5^{\circ} \mathrm{C}$ to $459.7^{\circ} \mathrm{C}$ and that should affect the solubility of $\mathrm{Fe}$ and $\mathrm{Al}$. At the end of the total melting of the ingot, it is possible to observe zones of liquid zinc with various temperatures lower than $460^{\circ} \mathrm{C}$ spreading over the bottom of the pot following a flow pattern very close to what was seen in Figure 6, where in region 4 there is an upward flow spreading over the entire domain.

As for the partial immersion condition of the ingot, Figures 9 to 12, for both the $50 \%$ and $25 \%$ immersion condition, the thermal heterogeneity of the bath is significantly lower when compared to the total immersion condition. It is possible to observe that at the end of the melting, under both conditions, the zones with liquid zinc with temperatures lower than $460^{\circ} \mathrm{C}$ are concentrated close to the ingot melting region. Referring once more to Figure 6, where a recirculation zone was seen next to region 7 , it is possible to understand why these zones of liquid zinc with lower temperatures do not spread throughout the pot, recirculation makes it difficult to move the fluid through convective currents.

With the partial immersion of the zinc ingot, the melting occurs closer to the bath surface and as the observed temperature differences are very close to the zinc bath surface, the top-dross particles, formed by this temperature reduction, would not spread throughout the zinc bath as they have approximately $40 \%$ lower density than the zinc bath at $460^{\circ} \mathrm{C}$, therefore they will precipitate on the surface of the bath relatively faster than in the full ingot immersion condition.

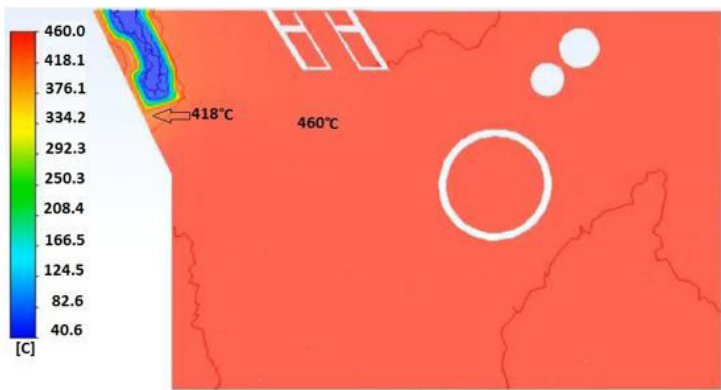

Figure 9. Temperature distribution with the solid ingot at $40^{\circ} \mathrm{C}$ $50 \%$ inserted into the zinc bath.

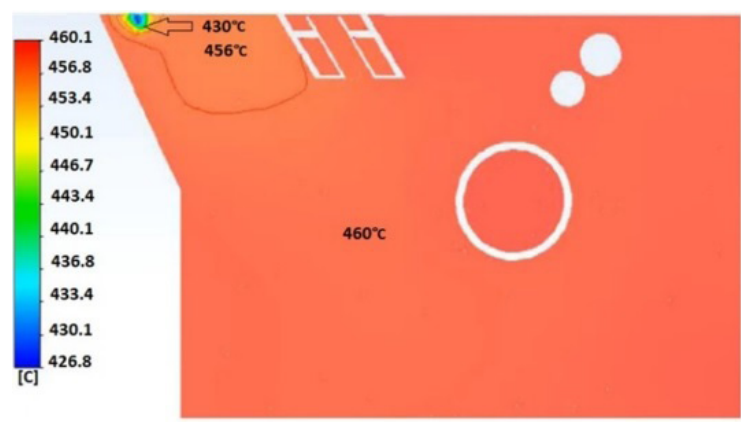

Figure 10. Temperature distribution after melting the $50 \%$ ingot inserted into the zinc bath after $7.6 \mathrm{~min}$.

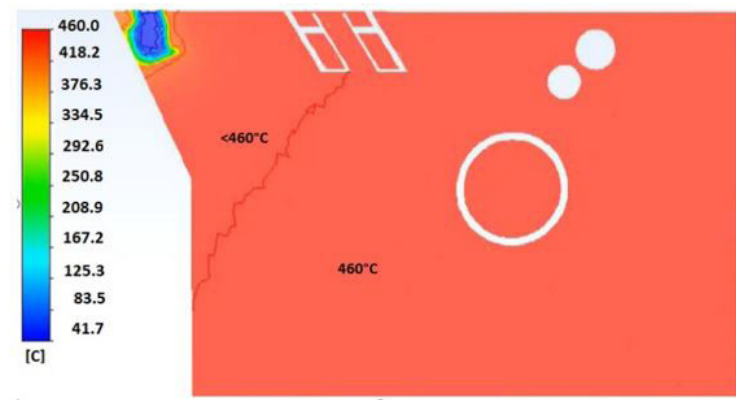

Figure 11. Temperature distribution with the solid ingot at $40^{\circ} \mathrm{C}$ $25 \%$ inserted in the zinc bath.

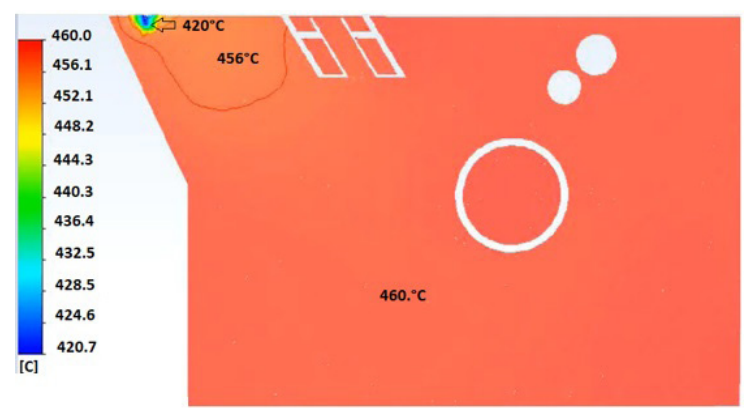

Figure 12. Temperature distribution after melting of the $25 \%$ ingot inserted into the zinc bath after $7.2 \mathrm{~min}$.

Comparing the three ingot immersion conditions, it can be seen that there is no significant difference in melting times. Melting times of $7.7 \mathrm{~min}, 7.6 \mathrm{~min}$ and $7.2 \mathrm{~min}$ were 
observed for the conditions of total immersion, $50 \%$ and $25 \%$ immersion conditions respectively. This is due to the fact that, although the ingot that was completely immersed has more mass for melting, it also has a greater surface area for thermal exchange, which leaves it in melting speed conditions similar to the partially immersed ingots.

Still comparing the results of the three conditions, the most significant difference between them is undoubtedly the greater thermal heterogeneity in the zinc bath in the ingot total immersion condition, in this condition the temperature reduction in the deepest part of the pot contributes to a potential formation of top-dross particles ${ }^{22,23,24}$, which as they are formed at the bottom of the pot, can be dragged by the flow currents in different directions.

\subsection{Effect on the trajectory of particles in the pot}

In Figure 13 the statistical data of the top-dross particles destinations calculated during the simulations can be seen. The trajectories of the top-dross particles, which were injected into the ingot fusion front, were simulated. The results of these trajectories confirmed that the deeper the ingot's immersion position, the greater the probability of the top-dross particles finding the strip inside the zinc bath. Furthermore, as seen in section 3.1, the deeper the ingot melting position, the greater the thermal imbalance of the bath and, therefore, the greater the precipitation of top-dross particles.

As can be seen in Figure 13, according to the definition of regions seen in Figure 3 in section 2.1, in the fusion of the inserted complete ingot, of the 2488 injected particles to represent the top-dross particles in this position, $25.31 \%$ found the strip in one of its 4 regions, $5.79 \%$ precipitated on the surface of the bath inside the snout, $55.02 \%$ precipitated on the free surface of the pot and $13.87 \%$ were still in transit after the end of $30 \mathrm{~min}$ of industrial process simulation.

On the other hand, in Figure 14, which refers to 50\% ingot immersion, where the trajectory and destination of the particles are also represented in a graph, it is possible to observe a very different condition, where of the 1172 particles injected into the ingot fusion front only $7.08 \%$ found the strip in one of its 4 regions, $2.13 \%$ precipitated on the surface of the internal bath in the snout, $86.01 \%$ precipitated on the free surface of the pot and $4.78 \%$ were still in transit after the end of the simulation that represented 30 minutes of industrial process.

In Figure 15 there is a graph of the distribution of topdross particles for the condition of the ingot immersed only $25 \%$ of its length, it can be seen that, just as there was a difference between the two other previous conditions, there were also differences observed in this condition. Of the 912 particles injected into the ingot fusion front, only $3.04 \%$ found the strip in one of its 4 regions, $0.33 \%$ precipitated on the surface of the internal bath in the snout, $90.68 \%$ precipitated on the free surface of the pot and 5.59\% were still in transit after the end of the simulation that represented 30 minutes of industrial process.

In general, comparing the three immersion conditions of the zinc ingot, it can be seen that in the condition of the ingot completely immersed in the bath, the top-dross particles generated from the ingot melting front were dragged by the upward flow of the zinc bath identified as region 4, seen in

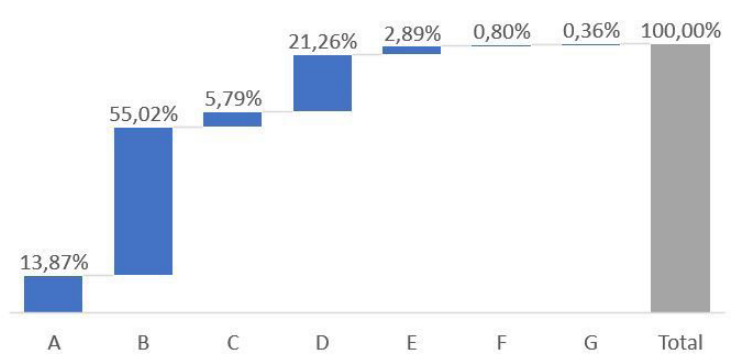

Figure 13. Destination of particles with ingot completely inserted $(\mathrm{A}=$ still in transit in the zinc bath; $\mathrm{B}=$ precipitated on the surface of the pot; $\mathrm{C}=$ precipitated on the surface of the internal snout bath; $\mathrm{D}=$ found the strip in region $1 ; \mathrm{E}=$ found the strip in region 2; $\mathrm{F}=$ found the strip in region $3 ; \mathrm{G}=$ found the strip in region 4).

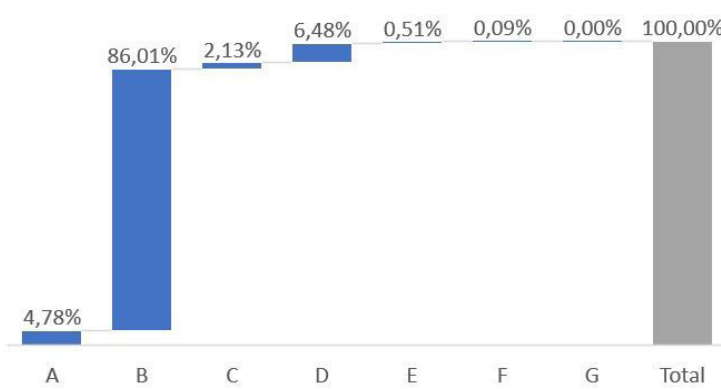

Figure 14. Destination of particles with half ingot inserted $(A=$ still in transit in the zinc bath; $\mathrm{B}=$ precipitated on the surface of the pot; $\mathrm{C}=$ precipitated on the surface of the internal snout bath; $\mathrm{D}=$ found the strip in region $1 ; E=$ found the strip in region $2 ; \mathrm{F}=$ found the strip in region $3 ; \mathrm{G}=$ found the strip in region 4 ).

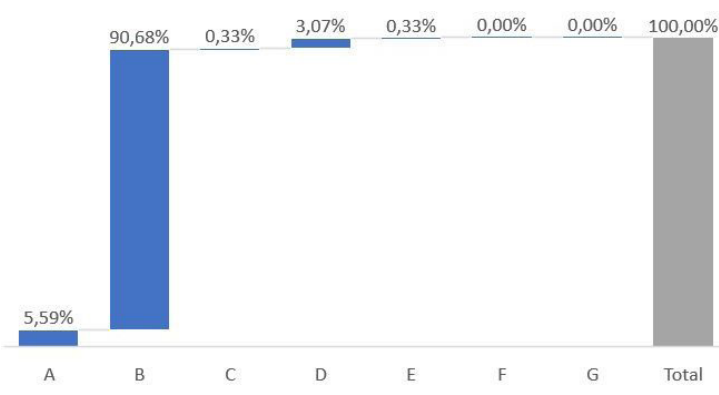

Figure 15. Destination of particles with $1 / 4$ ingot immersed $(A=$ still in transit in the zinc bath; $\mathrm{B}=$ precipitated on the surface of the pot; $\mathrm{C}=$ precipitated on the surface of the internal snout bath; $\mathrm{D}=$ found the strip in the region $1 ; \mathrm{E}=$ found the strip in region $2 ; \mathrm{F}=$ found the strip in region $3 ; \mathrm{G}=$ found the strip in region 4 ).

Figure 6 of section 3.1, and easily found the strip entering the pot and spread throughout the zinc bath. Whereas in the other two conditions, $50 \%$ and $25 \%$ ingot immersion, as the particles were formed closer to the surface, they precipitated on the surface of the zinc bath more quickly and therefore a smaller amount of particles found the strip inside the zinc bath.

Observing Figures 16 and 17, where are the images of the residence time of top-dross particles, of the conditions of total and partial immersion with $1 / 4$ of the immersed ingot, it is possible to notice the differences in the dispersion and quantity of top-dross particles that remained in the zinc bath 
Table 2. Destination of top-dross particles simulating 30-minute process.

\begin{tabular}{ccccccc}
\hline $\begin{array}{c}\text { Quantity of the } \\
\text { submerged ingot }\end{array}$ & Process speed & $\begin{array}{c}\text { Simulated } \\
\text { process time }\end{array}$ & $\begin{array}{c}\text { Processed } \\
\text { length }\end{array}$ & $\begin{array}{c}\text { Total particles } \\
\text { formed }\end{array}$ & $\begin{array}{c}\text { Particles that } \\
\text { found the strip }\end{array}$ & $\begin{array}{c}\text { Dross dragged by the } \\
\text { strip (particles/length) }\end{array}$ \\
\hline $100 \%$ & $150 \mathrm{~m} / \mathrm{min}$ & $30 \mathrm{~min}$ & $4500 * 2$ faces & 2488 & 630 & $7,00 \%$ \\
\hline $50 \%$ & $150 \mathrm{~m} / \mathrm{min}$ & $30 \mathrm{~min}$ & $4500 * 2$ faces & 1172 & 83 & $0,92 \%$ \\
\hline $25 \%$ & $150 \mathrm{~m} / \mathrm{min}$ & $30 \mathrm{~min}$ & $4500 * 2$ faces & 912 & 28 & $0,31 \%$ \\
\hline
\end{tabular}

Table 3. Destination of top-dross particles during 30min of industrial process.

\begin{tabular}{cccccc}
\hline $\begin{array}{c}\text { Quantity of the } \\
\text { submerged ingot }\end{array}$ & Process speed & $\begin{array}{c}\text { Simulated process } \\
\text { time }\end{array}$ & Processed length & $\begin{array}{c}\text { Particles that found } \\
\text { the strip }\end{array}$ & $\begin{array}{c}\text { Dross dragged by the } \\
\text { strip (particles/length) }\end{array}$ \\
\hline $100 \%$ & $150 \mathrm{~m} / \mathrm{min}$ & $30 \mathrm{~min}$ & $4500 * 2$ faces & 821 & $9,12 \%$ \\
\hline $50 \%$ & $150 \mathrm{~m} / \mathrm{min}$ & $30 \mathrm{~min}$ & $4500 * 2$ faces & 123 & $1,36 \%$ \\
\hline $25 \%$ & $150 \mathrm{~m} / \mathrm{min}$ & $30 \mathrm{~min}$ & $4500 * 2$ faces & 71 & $0,80 \%$ \\
\hline
\end{tabular}

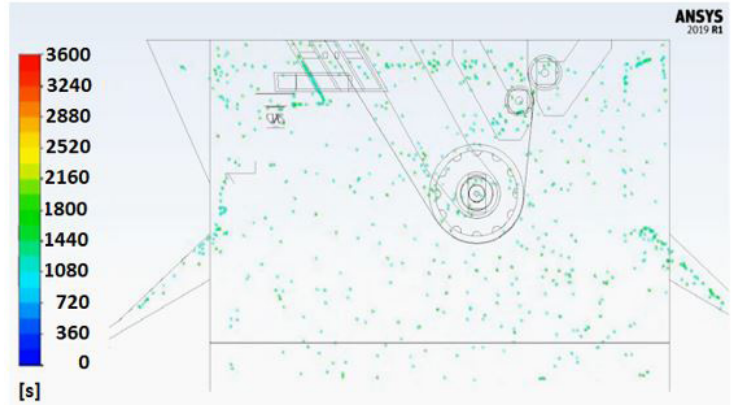

Figure 16. Top-dross particles generated from the fusion of the zinc ingot, completely immersed, still resident and dispersed in the galvanizing bath after $30 \mathrm{~min}$ (1800 s) of industrial process simulation.

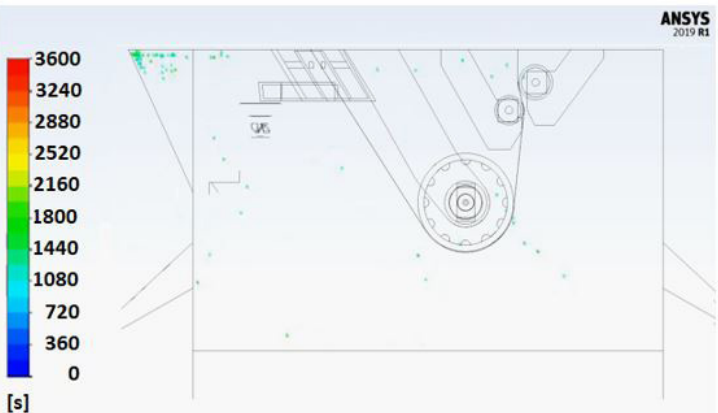

Figure 17. Top-dross particles generated from the fusion of zinc ingot, immersed $25 \%$, still resident and dispersed in the galvanizing bath after $30 \mathrm{~min}(1800 \mathrm{~s})$ of industrial process simulation.

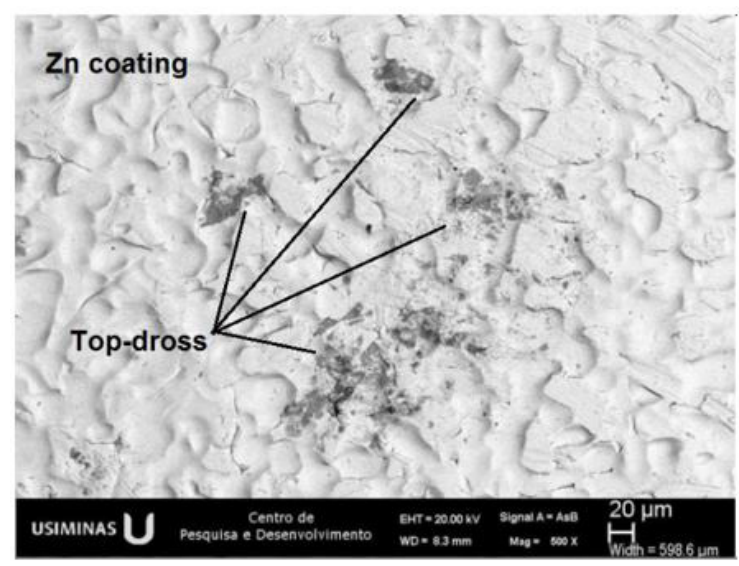

Figure 18. Surface aspect of the coating with top-dross particle with $500 \mathrm{X}$ magnification.

fusion front, while in the industrial condition the dross particles form, to a lesser extent, in the fusion front of the ingot and, also in the regions close to the strip, where there is detachment of iron from the strip to the zinc bath by dissolution and transport.

During the monitoring inspection of inspected materials for quantification of top-dross particles, some samples were selected for image and chemical composition analysis in SEM/ EDS. Images were taken of the surface of the cross section of a region of the sample with a dross drag particle seen in Figures 18 and 19. In Figure 18, it is possible to verify that 


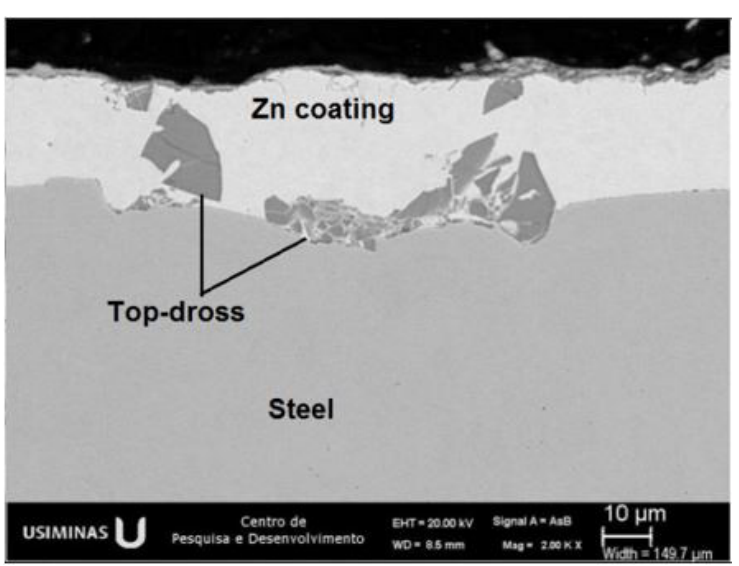

Figure 19. Cross-section aspect of the coating with top-dross particle with $2000 \mathrm{X}$ magnification.

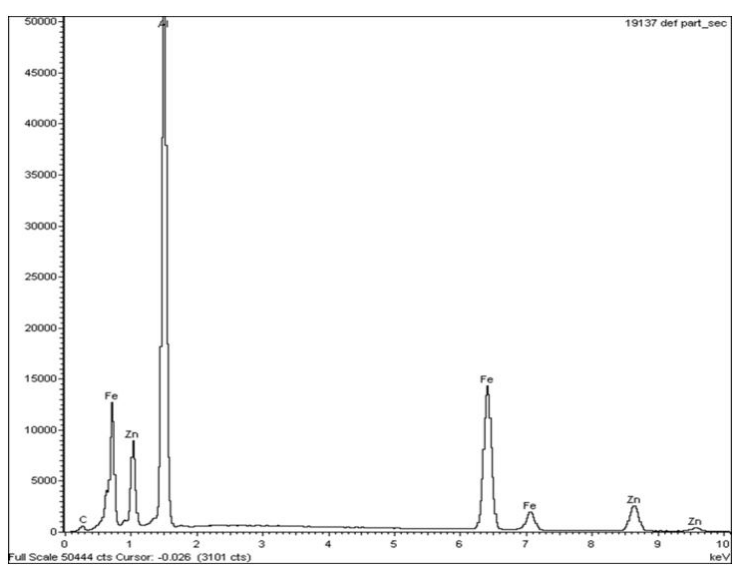

Figure 20. Spectrum of the chemical composition of the top-dross particle found in the zinc coating.

the particle appears on the surface of the galvanized material with a darker shade than the zinc coating, in Figure 19, it is possible to see in the cross section of the material the particle trapped inside the coating, also in a darker shade than the coating.

Figure 20 shows the chemical composition spectrum of the top-dross particles found in the coating of zinc-galvanized steel strips during the SEM/EDS analysis. It is possible to verify that in these chemical composition spectra there is a predominance in the presence of $\mathrm{Al}$, followed by $\mathrm{Fe}$ and with a lower participation of zinc, this result converges to a positive identification of a top-dross particle which, as seen in section 2.1, is composed of $\mathrm{Fe}, \mathrm{Al}$ and $\mathrm{Zn}$.

\section{Conclusions}

With the results of the computer simulation, it was possible to see that the greater the immersion of the solid zinc ingot in the galvanizing bath, the greater the thermal imbalance in the galvanizing pot, which favors the formation of larger amounts of top-dross particles. It was also observed that the greater the amount of top-dross particles formed, the greater the chances of these particles finding the strip and being dragged by it. Furthermore, the immersion depth of the ingot showed that the deeper the formation of the particles, the longer they circulate in the zinc bath. Comparing the industrial data with the simulation, it was possible to observe that the results are convergent and consistent with each other, which demonstrates the potential of this tool to identify the phenomena involved in the production process of hot-dip galvanized materials. Then, after a detailed analysis, some solutions are proposed to be validated industrially during the production of galvanized materials. As it was done in this study, where according to the results found and validated industrially, it is recommended to insert the ingot in the zinc bath gradually, without allowing it to be deeply immersed in the bath during the melting process.

\section{References}

1. Vieira RR, Ferreira JL. Process control of galvanized material. 19th Rolling Conference IAS 2012; 2012. p 32.

2. Park JH, Park G-H, Paik D-J, Huh Y, Hong M-H. Influence of aluminum on the formation behavior of $\mathrm{Zn}-\mathrm{Al}-\mathrm{Fe}$ intermetallic particles in a zinc bath. Metallurgical and Materials Transaction. 2012;43A:195.

3. Sippola P, Smith D. Use of high zinc bath entry strip temperature to solve coating problems. Corrosion Science and Technology. 2010;9:175.

4. Ajersch F, Ilinca F, Hétu J-F, Goodwin FE. Numerical simulation of flow, temperature and composition variations in a galvanizing bath. Can Metall Q. 2005;43:369.

5. Dash SK, Dutta M, Rajesh N. Use of flow barriers to eliminate vortex in the flow field generation in a continuous galvanizing bath. ISIJ Int. 2005;45:1059.

6. Ilinca F, Ajersch F, Baril C, Goodwin FE. Numerical simulation of the galvanizing process during GA to GI transition. Int $\mathrm{J}$ Numer Methods Fluids. 2007;53:1629.

7. Kim HS, Kim JG, Yoon SC, Im HJ, Moon MB. Numerical simulation of flow and dross particles transfer in a $55 \% \mathrm{Al}-\mathrm{Zn}$ pot. Corrosion Science and Technology. 2010;11(3):71.

8. Tang N. Refined $450^{\circ} \mathrm{C}$ isotherm of $\mathrm{Zn}-\mathrm{Fe}-\mathrm{Al}$ phase diagram. Mater Sci Technol. 1995;11:871.

9. Reiss G, Ishmurzin A, Mugrauer C, Eß1 W, Ecker W, Strutzenberger $\mathrm{J}$, et al. Thermo-chemical fluid flow simulation in hot-dip galvanizing: the evaluation of dross build-up formation. Metall Mater Trans B . 2019.

10. Ajersch F, Ilinca F, Hétu J-F. Numerical analysis of the effect of temperature variation on flow in a continuous galvanizing bath. 44th MWSP Conference Proceeding; 2002; p. 863.

11. Madal GK, Balasubramaniam R, Mehrotra SP. Theoretical investigation of the interfacial reactions during hot-dip galvanizing of steel. Metall Mater Trans, A Phys Metall Mater Sci. 2009;40A:637.

12. Vieira RR, Eleutério HL, Oliveira TG, Bagatini MC, Tavares RP. Numerical simulation of zinc flow in different layouts of galvanization pot. Mater Res. 2021;24:477.

13. Voller VR. Technical report. Modeling Solidification Processes. Mathematical Modeling of Metals Processing Operations Conference; Palm Desert: American Metallurgical Society; 1987.

14, Voller VR, Brent AD, Reid KJ. Technical report. A computational modeling framework for the analysis of metallurgical solidification process and phenomena. Conference for Solidification Processing Ranmoor House; Sheffield; 1987.

15. Voller VR, Prakash C. A fixed-grid numerical modeling methodology for convection-diffusion mushy region phasechange problems. Int J Heat Mass Transfer. 1987;30:1709. 
16. Ajersch F, Ilinca F, Hétu J-F. Simulation of flow in a continuous galvanizing bath: Part I thermal effects of ingot addition. Metall Mater Trans, B, Process Metall Mater Proc Sci. 2004;35B:161.

17. Ajersch F, Ilinca F, Hétu J-F. simulation of flow in a continuous galvanizing bath: Part II transient aluminum distribution resulting from ingot addition. Metall Mater Trans, B, Process Metall Mater Proc Sci. 2004;35B:171.

18. Zhou X, Yuan S, Huang Y, Yang P, Zhou X. Simulation of special flow affecting dross formation on steel strip in galvanising bath. Ironmak Steelmak. 2015;42:785.

19. Park HS, Han KA, Lee J, Shim JW. Numerical simulation of zinc flow and temperature distribution in a galvanizing zing pot. ISIJ Int. 2008;48:224.

20. Peters KJ, Hüstrung J, Göhler K. Simulation of galvanising process at Thyssenkrupp Steel Europ. International Conference on Zinc and Zinc Alloy Coated Steel Sheet Proceedings; 2007). p. 281.

21. Kim YH, Cho YW, Chung S-H, Shim J-D, Ra HY. Numerical analysis of flow and heat transfer in molten zinc pot of continuous hot-dip galvanizing line. ISIJ Int. 2000;40:706.

22. Lee SJ, Kim S, Koh MS, Choi Jh. Flow field analysis inside a molten zn pot the continuous hot-dip galvanizing process. ISIJ Int. 2002;42:407.

23. Ajersch F, Ilinca F, Hétu J-F, Goodwin FE. Numerical simulation of the rate of dross formation in continuous galvanizing baths. Proceeding of the Iron and Steel Technology Conference and Exposition; 2005, 1.

24. Sawaitul P, Chowriwar SA, Lade P. Minimizations of dross formation during the continuous galvanizing process in the steel industry. Int J Emerg Technol Adv Eng. 2012;2:45. 